\title{
The effect of breed on fatty acid composition of subcutaneous adipose tissues in fat-tailed sheep under identical feeding conditions
}

\author{
E. Maleki ${ }^{1}$, F. Kafilzadeh ${ }^{1 \#}$, G.Y. Meng ${ }^{2,3}$, M.A. Rajion ${ }^{2}$ \& M. Ebrahimi ${ }^{2}$ \\ ${ }^{1}$ Department of Animal Science, Faculty of Agriculture, Razi University, Kermanshah, Iran \\ ${ }^{2}$ Department of Veterinary Preclinical Sciences, Faculty of Veterinary Medicine, Universiti Putra Malaysia, 43400 \\ Serdang, Selangor, Malaysia \\ ${ }^{3}$ Institute of Tropical Agriculture, Universiti Putra Malaysia, 43400 UPM, Serdang, Selangor, Malaysia
}

(Received 11 September 2014; Accepted 5 January 2015; First published online 23 February 2015)

Copyright resides with the authors in terms of the Creative Commons Attribution 2.5 South African Licence.

See: http://creativecommons.org/licenses/by/2.5/za

Condition of use: The user may copy, distribute, transmit and adapt the work, but must recognise the authors and the South African Journal of Animal Science.

\begin{abstract}
A study was conducted to evaluate the fatty acid (FA) profile of subcutaneous adipose tissue and tailfat of two fat-tailed sheep breeds under identical feeding conditions. Twelve male lambs from two breeds, Sanjabi $(n=6)$, weighing $23.3 \pm 0.48 \mathrm{~kg}$, and Mehraban $(n=6)$, weighing $26.1 \pm 2.14 \mathrm{~kg}$, were used in this investigation. All animals were weighed and slaughtered at the end of a 90-day fattening period and FA composition of subcutaneous adipose tissue and tailfat was determined. Significant breed differences in total FA, total polyunsaturated fatty acid (PUFA) and n-6PUFA contents were observed in the subcutaneous adipose tissue, but not in the tailfat. Breed differences were observed in the conjugated linoleic acid (CLA) content of subcutaneous adipose tissue, with higher levels in Sanjabi than in Mehraban lambs. Linoleic and a-linolenic acid of subcutaneous adipose were significantly higher in the Sanjabi breed than in the Mehraban breed. Thus, adipose tissue from fat-tailed Sanjabi lamb has a higher proportion of health-promoting linoleic and $\alpha$-linolenic acids, unsaturated fatty acids (UFA) and CLA, suggesting that the Sanjabi breed could be used for producing healthier lamb products.
\end{abstract}

Keywords: Fatty acid profile, Iranian sheep breeds, Mehraban lamb, Sanjabi lamb

\# Corresponding author: kafilzadeh@razi.ac.ir

\section{Introduction}

Fatty acids (FA) or lipids are a class of bio-compounds that play a significant role in cellular function and health. Fats are an important part of a balanced diet for human beings and are essential for the digestion of the fat-soluble vitamins A, D, E and K. Human beings, like all vertebrates and most animals, display an absolute dietary requirement for linoleic (C18:2n-6) and $\alpha$-linolenic acid (C18:3n-3). Both linoleic acid and $\alpha$-linolenic acid are polyunsaturated and serve as precursors for other important compounds, for instance, $\alpha$-linolenic acid is the precursor for long-chain n-3 polyunsaturated fatty acid (PUFA) such as docosahexaenoic acid (DHA). Likewise, linoleic acid is the parent FA in n-6 PUFA (Ruxton et al., 2004).

Bulliyya (2000) pointed out that many of today's common health problems and pathologies throughout the world can be related to changes in fat intake worldwide. According to Healy et al. (2000), these FAs are incorporated into all lipid membrane tissues, that is, all the immune system tissues and cells, through the consumption of n-3PUFA (Maroufyan et al., 2012). Skin function and normal growth are maintained because of C18:3n-3 (Fu \& Sinclair 2000). However, the physiological importance of n-6PUFA for humans has been confirmed for example, mammalian skin function, growth and reproduction are affected by a C18:2n-6 deficiency (Burr, 1973; Holman, 1977; Hansen \& Jensen, 1985). According to Wahle et al. (2004) and Kelley et al. (2010), a group of geometric and positional isomers of linoleic acid are referred to as conjugated linoleic acid (CLA) (C18:2n-6), in which the double bonds are joined together. Research showed that CLA possesses anti-adipogenic, anti-atherogenic, anti-carcinogenic, anti-inflammatory and anti-diabetogenic properties. Kelley et al. (2010) pointed out that one of the richest natural sources of CLA isomers, especially rumenic acid (cis-9 trans-11 CLA), is ruminant fats. There is evidence to suggest that the CLA content in ruminant adipose tissues varies. Danc et al. (2009) reported differences in the CLA content of subcutaneous adipose tissue of beef cattle breeds. Wachira et al. (2002) also reported differences in the FA content of subcutaneous adipose tissues of the Suffolk, Soay and Friesland sheep breeds. 
The Sanjabi and Mehraban are Iranian fat-tailed sheep breeds. They are well adapted to cold environmental conditions and are reared mainly for meat. Although this sheep's tailfat is available in Iran, it cannot be used effectively in the food or confectionery industry. Furthermore, little research has been done on the FA composition of the tailfat of sheep. There is also limited information on the FA composition of their subcutaneous adipose tissues. Therefore, the aim of the present study was to measure the FA profile of the tailfat and subcutaneous adipose tissues in Sanjabi and Mehraban sheep maintained under identical feeding conditions.

\section{Materials and Methods}

The experiment was carried out at the Experimental Farm of the School of Agriculture, Razi University, Kermanshah, Iran. Two fat-tailed sheep breeds, the Sanjabi and Mehraban, were used.

Lambs were born from oestrus-synchronized ewes that were maintained under similar conditions and that received a similar diet containing lucerne hay, maize grain, soybean meal, wheat bran, salt and mineral premix. The forage/concentrate ratio was 60/40 and formulated according to NRC (2001) recommendations. Prior to initiation of the growth study, the lambs were maintained with their dams and had access to concentrate, lucerne hay and water until weaning at 90 days of age. After weaning, 12 male lambs from the two breeds, namely Sanjabi $(n=6)$, weighing $23.33 \pm 0.48 \mathrm{~kg}$, and Mehraban $(n=6)$, weighing $26.10 \pm 2.14$ $\mathrm{kg}$, were selected for the experiment. The lambs were drenched against parasites and housed individually in metal-framed pens $(2 \mathrm{~m} \times 1 \mathrm{~m})$, with slatted flooring 0.5 metre above the ground. All lambs received a similar pelleted diet and had access to water ad libitum during the fattening period of three months. The forage/concentrate ratio in the pelleted diet was 30/70, formulated according to NRC (1985) The diet consisted of $30 \%$ lucerne hay, $28 \%$ barley, $25 \%$ maize, $8 \%$ soybean meal, $5 \%$ wheat bran, $2.5 \%$ molasses, $0.5 \%$ dicalcium phosphate, $0.5 \%$ vitamin/mineral premix and $0.5 \%$ salt. Chemical composition and the FA profile of the pelleted diet are presented in Table 1. Lambs were weighed at monthly intervals and at the end of the fattening period after a $14 \mathrm{~h}$ fasting (with access to water), and slaughtered. Three grams subcutaneous fat were taken from between the eighth and ninth ribs of the carcass and from tailfat, and frozen at $-20^{\circ} \mathrm{C}$, pending $\mathrm{FA}$ analysis.

Samples of the diet $(500 \mathrm{~g})$ were collected every $7 \mathrm{~d}$ and stored at $4{ }^{\circ} \mathrm{C}$. Feed refusals for each lamb were weighed daily and stored at $4{ }^{\circ} \mathrm{C}$ until analysed for dry matter (DM). Feed samples were dried at $60^{\circ} \mathrm{C}$ for $48 \mathrm{~h}$ to determine the DM content, ground to pass a $1 \mathrm{~mm}$ screen, and analysed for crude protein (CP), ether extract (EE), ash, organic matter (OM), neutral detergent fibre (NDF) and acid detergent fibre (ADF) according to standard AOAC methods (AOAC, 1990). Crude protein (CP, total nitrogen $\times 6.25$ ) was determined by method number 990.03 of the AOAC (1990). Neutral detergent fibre and ADF were determined according to Van Soest et al. (1991).

Total FAs were extracted from the feed and fat, using the method of Folch et al. (1957) with some modifications by Rajion et al. (1985) as described by Ebrahimi et al. (2012), using chloroform : methanol (2 : $1 \mathrm{v} / \mathrm{v}$ ) containing butylated hydroxyl toluene to prevent oxidation during sample preparation. One gram of the experimental diet and $0.5 \mathrm{~g}$ tissue were homogenized in $40 \mathrm{~mL}$ chloroform : methanol $(2: 1 \mathrm{v} / \mathrm{v})$ using an Ultra-Turrax T5 FU homogenizer (IKA AnalysentechnikGmBH, Heidolph, Viertrieb, Germany) in a 50-mL stoppered ground-glass extraction tubes. Transmethylation of the extracted FAs to their fatty acid methyl esters (FAME) was carried out using $0.66 \mathrm{~N} \mathrm{KOH}$ in methanol and $14 \%$ methanol boron trifluoride $\left(\mathrm{BF}_{3}\right)$ (Sigma Chemical) according to the methods by AOAC (2007), as described by Ebrahimi et al. (2012). The FAME were separated by gas chromatography (Agilent 7890A), using a Supelco SP 2560 capillary column of $100 \mathrm{~m} \times 0.25 \mathrm{~mm}$ ID $\times 0.2 \mu \mathrm{m}$ film thickness (Supelco, Bellefonte, PA, USA). One microlitre was injected by an auto sampler (Agilent Auto Analyzer 7683 B series, Agilent Technologies, Santa Clara, Calif, USA) into the chromatograph, equipped with a split/splitless injector and a flame ionization detector. The carrier gas was nitrogen at a flow rate of $1.2 \mathrm{~mL} / \mathrm{min}$. The split ratio was $1: 20$ after injection of $1 \mu \mathrm{L}$ of the FAME. The injector temperature was programmed at $250{ }^{\circ} \mathrm{C}$, and the detector temperature was $270{ }^{\circ} \mathrm{C}$. The column temperature programme ran at $150^{\circ} \mathrm{C}$ for $2 \mathrm{~min}$, warmed to $158^{\circ} \mathrm{C}$ at $1^{\circ} \mathrm{C} / \mathrm{min}$, held for $28 \mathrm{~min}$, warmed to $220^{\circ} \mathrm{C}$ at $1{ }^{\circ} \mathrm{C} / \mathrm{min}$, and then held for $20 \mathrm{~min}$ to achieve satisfactory separation (Ebrahimi et al., 2013). The peaks of samples were identified, and concentrations calculated based on the retention time and peak area of known standards (Sigma Chemical). The FA concentrations are expressed as percentage of identified FAs in each sample.

All data were analysed using the GLM procedures of SAS (SAS, 2003). The following model was used:

$$
Y i j=I+D i+S j+e i j
$$

where Yij represents an observation; I is the overall mean; Di is the effect of the breed ( $i=$ Mehraban, Sanjabi); $\mathrm{Sj}$ is the animal effect and eij is the residual error. Least significant difference comparison 
procedures were used for mean separation in the presence of a significant F-statistic. All statistical tests were conducted at $95 \%$ confidence level.

Table 1 Chemical composition (\% of dry matter, DM) and fatty acid (FA) profile (\% of total identified fatty acids) in the experimental diet

\begin{tabular}{lclc}
\hline $\begin{array}{l}\text { Dietary chemical } \\
\text { composition }\end{array}$ & g/kg DM & Fatty acids & $\begin{array}{c}\text { \% of total } \\
\text { identified FA }\end{array}$ \\
\hline Dry matter & 911 & C10:0 & 0.06 \\
Organic matter & 910 & C12:0 & 0.38 \\
Crude protein & 153.4 & C14:0 & 0.53 \\
Ether extract & 23.0 & C15:0 & 0.46 \\
Neutral detergent fibre & 328.7 & C16:0 & 19.45 \\
Acid detergent fibre & 186.7 & C16:1 & 0.69 \\
& & C18:0 & 5.95 \\
& & C18:1n-9 & 20.68 \\
& & C18:2n-6 & 44.57 \\
& & C18:3n-6 & 0.78 \\
& & C18:3n-3 & 6.44 \\
& & Total SFA & 26.84 \\
& & Total UFA & 73.16 \\
& & Total MUFA & 21.37 \\
& & Total n-3PUFA & 6.44 \\
& & Total n-6PUFA & 44.57 \\
& & Total PUFA & 51.02 \\
& & n-6: n-3 ratio & 6.92
\end{tabular}

SFA: saturated FAs; MUFA: monounsaturated FAs; PUFA: polyunsaturated FAs.

Total SFA = sum of C14:0+C15:0+C16:06+C18:0;

Total UFA = sum of C16:1+C18:1n-9+C18:2n-6+C18:3n-6+C18:3n-3;

Total MUFA = sum of C16:1+C18:1n-9;

Total n-3PUFA = sum of C18:3n-3;

Total n-6 PUFA = sum of C18:2n-6;

Total PUFA = sum of C18:3n-3+C18:2n-6;

$n-6: n-3$ ratio = sum total $n-6$ PUFA; sum of total $n-3 P U F A$.

\section{Results and Discussion}

The FA composition of subcutaneous adipose tissue and tailfat is expressed as a percentage of total identified FAs (Tables 2 and 3). The average daily feed $(\mathrm{g})$ consumed by the Sanjabi and Mehraban breeds was $1192.6 \pm 56.57 \mathrm{~g}$ and $1338.8 \pm 58.98 \mathrm{~g}$, respectively, and was not significantly different between breeds $(P<0.05)$. Breed affected the FA composition of subcutaneous adipose tissue significantly. Differences in the FA composition of fat have been observed between sheep breeds (Sanudo et al., 2000) and beef cattle breeds (Laborde et al., 2001; Dance et al., 2009). However, results from these studies are confounded because the two breeds were from different regions and kept under different management and feeding conditions, contrary to the present study where the two breeds were under identical management and feeding conditions. To the researchers' knowledge, no information is available on the FA profiles of the Sanjabi and Mehraban sheep breeds and how they compare. The synthesis and metabolism of FAs in the ruminant animal could be affected by genetic and microbial activities in the rumen. Saatchi et al. (2013) demonstrated that the heritability of FAs varies with chain length. FAs with a chain length of $>18$ carbons (with the exception of $\mathrm{C} 24: 0$ ) had lower heritabilities (0.06 to 0.24$)$ than FAs with shorter chains (0.08 to 0.57). 
Table 2 Fatty acid (FA) composition (\% total identified fatty acids) (mean \pm SE; $n=6$ ) in subcutaneous adipose tissue of two fat-tailed sheep breeds, Mehraban and Sanjabi

\begin{tabular}{|c|c|c|c|}
\hline Fatty acids & Mehraban & Sanjabi & $P$-value \\
\hline C10:0 & $0.40 \pm 0.06$ & $0.52 \pm 0.10$ & 0.325 \\
\hline C12:0 & $0.24 \pm 0.03$ & $0.18 \pm 0.03$ & 0.198 \\
\hline C14:0 & $5.17 \pm 0.32$ & $4.12 \pm 0.37$ & 0.039 \\
\hline C14:1 & $0.95 \pm 0.04$ & $0.93 \pm 0.12$ & 0.883 \\
\hline C15:0 & $1.33 \pm 0.10$ & $1.52 \pm 0.31$ & 0.589 \\
\hline C16:0 & $28.9 \pm 0.83$ & $26.6 \pm 0.58$ & 0.031 \\
\hline C16:1 & $3.62 \pm 0.23$ & $3.14 \pm 0.26$ & 0.250 \\
\hline C17:0 & $0.43 \pm 0.05$ & $0.49 \pm 0.13$ & 0.717 \\
\hline C17:1 & $3.97 \pm 0.20$ & $4.62 \pm 0.50$ & 0.331 \\
\hline C18:0 & $8.96 \pm 0.47$ & $9.22 \pm 0.70$ & 0.798 \\
\hline C18:1n-9 & $37.9 \pm 1.45$ & $37.8 \pm 0.86$ & 0.975 \\
\hline C18:1t-11 & $3.40 \pm 0.33$ & $4.18 \pm 0.64$ & 0.375 \\
\hline C18:2n-6 & $3.02 \pm 0.13$ & $4.52 \pm 0.39$ & 0.012 \\
\hline C18:3n-6 & $0.15 \pm 0.05$ & $0.30 \pm 0.09$ & 0.178 \\
\hline c-9 t-11CLA & $0.73 \pm 0.06$ & $1.15 \pm 0.18$ & 0.052 \\
\hline$c-12 \mathrm{t}-10 \mathrm{CLA}$ & $0.28 \pm 0.06$ & $0.22 \pm 0.04$ & 0.325 \\
\hline C18:3n-3 & $0.35 \pm 0.02$ & $0.59 \pm 0.05$ & 0.009 \\
\hline$C 20: 4 n-6$ & $0.14 \pm 0.01$ & $0.17 \pm 0.02$ & 0.068 \\
\hline$C 20: 5 n-3$ & $0.28 \pm 0.08$ & $0.36 \pm 0.10$ & 0.533 \\
\hline C22:5n-3 & $0.27 \pm 0.07$ & $0.26 \pm 0.09$ & 0.928 \\
\hline$C 22: 6 n-3$ & $0.29 \pm 0.10$ & $0.23 \pm 0.01$ & 0.754 \\
\hline Total SFA & $45.4 \pm 1.07$ & $42.7 \pm 0.82$ & 0.068 \\
\hline Total UFA & $54.6 \pm 1.07$ & $57.3 \pm 0.82$ & 0.068 \\
\hline Total MUFA & $49.8 \pm 1.11$ & $50.7 \pm 0.66$ & 0.531 \\
\hline Total n-3 PUFA & $1.20 \pm 0.20$ & $1.45 \pm 0.20$ & 0.443 \\
\hline Total n-6 PUFA & $3.16 \pm 1.11$ & $4.69 \pm 0.40$ & 0.011 \\
\hline Total PUFA & $4.35 \pm 0.30$ & $6.14 \pm 0.56$ & 0.016 \\
\hline Total trans FA & $3.40 \pm 0.33$ & $4.18 \pm 0.64$ & 0.374 \\
\hline Total CLA & $1.00 \pm 0.08$ & $1.37 \pm 0.19$ & 0.117 \\
\hline$n-6: n-3$ ratio & $2.98 \pm 0.47$ & $3.71 \pm 0.38$ & 0.311 \\
\hline UFA: SFA ratio & $1.21 \pm 0.05$ & $1.35 \pm 0.04$ & 0.070 \\
\hline PUFA: SFA ratio & $0.10 \pm 0.01$ & $0.14 \pm 0.01$ & 0.007 \\
\hline
\end{tabular}

SE: standard error; CLA: conjugated linoleic acid; UFA: unsaturated fatty acids;

SFA: saturated fatty acids; MUFA: monounsaturated fatty acids; PUFA: polyunsaturated fatty acids.

Total SFA $=$ sum of $C 10: 0+C 12: 0+C 14: 0+C 15: 0+C 16: 0+C 17: 0+C 18: 0$

Total UFA $=$ sum of $\mathrm{C} 14: 1+\mathrm{C} 16: 1+\mathrm{C} 17: 1+\mathrm{C} 18: 1 \mathrm{n}-9+\mathrm{C} 18: 2+\mathrm{C} 18: 3 \mathrm{n}-6+\mathrm{C} 18: 3 \mathrm{n}-3+$

$\mathrm{C} 20: 4+C 20: 5 n-3+C 22: 5 n-3+C 22: 6 n-3 ;$ Total MUFA = sum of C14:1 + C16:1 + C17:1 + C18:1n-9;

Total n-3 PUFA = sum of C18:3n-3 + C20:5n-3 + C22:5n-3 + C22:6n-3;

Total $n-6$ PUFA $=$ sum of $C 18: 2 n-6+C 18: 3 n-6+C 20: 4 n-6$;

Total PUFA $=$ sum of C18:2n-6+C18:3n-6+C18:3n-3 +C20:4n-6+C20:5n-3 + C22:5n-3 + C22:6n-3;

Total trans fatty acid = sum of C18:1t-11;

Total CLA = sum c-9 t-11CLA + c-12 t-10CLA;

$\mathrm{n}-6: \mathrm{n}-3$ ratio $=$ total $\mathrm{n}-6$ PUFA; total n-3 PUFA.

Palmitic acid (C16:0), stearic acid (C18:0) and myristic acid (C14:0) were the major SFAs in the subcutaneous adipose tissue and tailfat of the two breeds. The levels of C16:0 (28.9\% vs. 26.6\%) and C14:0 
(5.17\% vs. $4.12 \%)$ in the subcutaneous adipose tissue of the Mehraban were significantly $(P<0.05)$ higher than in the Sanjabi. Similar breed differences have been reported by Wachira et al. (2002), who found that myristic acid concentration was significantly higher in the subcutaneous adipose tissue of Friesland and Soay, compared with Suffolk lambs. The levels of stearic acid in the Sanjabi and Mehraban breed were $8.96 \%$ and. $9.22 \%$ in the present study, which are lower than those of Wachira et al. (2002), who reported values of $14.7 \%-18.7 \%$ for three lamb breeds that were fed a control diet.

The concentrations of palmitic acid $(26.5 \%$ vs. $25.7 \%)$, stearic acid $(11.01 \%$ vs. $7.11 \%)$ and myristic acid $(4.31 \%$ vs. $4.28 \%)$ of tailfat in the Sanjaibi and Mehraban breeds were not significantly different $(P$ $>0.05)$. The C18:0 values (7.11 - 11.01) of tailfat in the current study were similar to values reported by Nuernberg et al. (2008) for Skudde lambs (9.40 - $11.96 \mathrm{~g} / 100 \mathrm{~g})$, but lower than those of ewes of the Han (9.92 - $14.57 \mathrm{~g} / 100 \mathrm{~g})$ (Peng et al., 2010) and Damara (13\% of total FAs) (Alvice et al., 2013), suggesting a breed effect. Similar concentrations of palmitic acid (27.47\%) and myristic acid (6.70\%) were observed by Alipanah \& Kashan (2011) for tailfat of other Iranian sheep breeds. Alvice et al. (2013) recently reported lower concentrations (16.5\% and $2 \%)$ for palmitic and myristic acid, respectively, in the tailfat of the Damara breed. The levels of C15:0 (1.58\% vs. $0.87 \%)$ and C17:0 (0.70\% vs. $0.38 \%)$ in the tailfat of Sanjabi lambs were significantly $(P<0.05)$ higher than in that of Mehraban lambs.

Subcutaneous adipose tissue of Sanjabi contained less saturated fatty acids (SFA) $(42.7 \%$ of total FAs) and more unsaturated fatty acids (UFA) (57.3\%) compared with the Mehraban (45.4\% and 54.6\%, respectively). This resulted in a slightly higher UFA : SFA ratio for subcutaneous adipose (1.35) of the Sanjabi compared with the Mehraban (1.21). The high concentration of C18:2n-6 and C18:3n-3, and the low concentration of palmitic acid (C16:0) and myristic acid (C14:0) in subcutaneous adipose of the Sanjabi was responsible for these differences. The de novo FA synthesis in ruminants is limited primarily to 14,16 and 18 carbon FAs. Since the heritability of these FAs is higher than that of long-chain FAs, the differences in the content of palmitic acid (C16:0) and myristic acid (C14:0) of the adipose tissue between the Sanjabi and Mehraban breeds might be attributed to genetic differences.

Based on the present study, tailfat from the two breeds contained $42 \%$ SFA and 58\% UFA, consistent with results of Alipanah \& Kashan (2011), who reported that average percentages of the sheep tailfat were between $39.4 \%$ and $65.4 \%$ for SFA and between $32.2 \%$ and $60.8 \%$ for UFA.

Oleic acid (C18:1n-9) was the major monounsaturated fatty acid (MUFA), which contributed to more than $90 \%$ of the total MUFA in both subcutaneous adipose tissue and tailfat of the two breeds (Tables 2 and 3). The concentrations of C14:1, C16:1 and C17:1 in subcutaneous adipose were the reason for the major differences in FA composition between the breeds, and were significantly higher in the Sanjabi than the Mehraban.

The levels of the major contributors of n-6PUFA, namely C18:2n-6 (4.52\% vs. $3.02 \%)$ in Sanjabi lambs, were significantly higher than in the Mehraban $(P<0.05)$. However, the levels of C18:2n-6, C18:3n-6, C20:4n-6 and total n-6PUFA in the tailfat were not significantly different between the breeds. The levels of C20:5n-3, C22:5n-3, C22:6n-3 and total n-3PUFA were not significantly different between the breeds, either, but C18:3n-3 in the subcutaneous adipose tissue of the Sanjabi breed was higher $(P<0.05)$ than in the Mehraban. Nfor et al. (2014) reported similar results on cattle muscle. He recorded that the Gudali breed contained higher concentrations of $\mathrm{C} 18: 3 n-3$ in their muscles compared to the White Fulani. The levels of individual n-3PUFA and total n-3PUFA in the tailfat were not significantly different between the breeds.

Subcutaneous adipose tissue of the Sanjabi contained a higher total PUFA (6.14\% vs. 4.35\%) concentration and PUFA : SFA ratio (0.14 vs. 0.10$)$ than the Mehraban. The high concentrations of $\mathrm{C} 18: 2 \mathrm{n}-6$ and C18:3n-3, and consequently, the slightly higher content of C20:4n-6 in the subcutaneous adipose of the Sanjabi, were responsible for this significant difference. The high content of n-6 PUFA in Sanjabi is largely owing to the high content of linoleic acid of subcutaneous adipose tissue. However, the higher content of C18:2n-6 might be the driving force for the synthesis of C20:4n-6 in this breed. These findings on the n-6PUFA content of Sanjabi subcutaneous adipose are similar to those reported by Fisher et al. (2000) for Soay lambs, which, when compared with the Suffolk, had higher concentrations of n-6PUFA in their semimembranosus muscle. This could be owing to the low concentration of total lipids in muscle and a higher ratio of phospholipids to total lipids. The similar quantities of the long chain n-3PUFA in the muscles of the two breeds indicated similar quantities of phospholipids in their muscles and a similar metabolism of C18:3n-3 to produce these FAs.

The PUFA : SFA ratio of the tailfat was similar to that in the adipose tissue of the two breeds. The PUFA : SFA ratio in the Sanjabi and Mehraban breeds is consistent with the results of Alipanah \& Kashan, (2011), who reported values of between $0.069 \%$ and $0.195 \%$ for sheep breeds.

The levels of the C18:1t-11 (3.40\%- 4.18\%) and c-12 t-10 CLA $(0.22 \%-0.28 \%)$ of subcutaneous adipose tissue were not significantly different $(P>0.05)$ between the breeds, but c- 9 t-11 CLA levels $(0.73 \%$ $1.15 \%)$ in the subcutaneous adipose tissue of Sanjabi were higher $(P<0.05)$ than in the Mehraban. The 
levels of C18:1t-11 (3.41\% - 3.84\%) and c-9 t-11 CLA (1.18\% - 1.50\%) and c-12 t-10 CLA (0.15\% - 0.17\%) in the tailfat were not significantly different between the breeds.

Table 3 Fatty acid (FA) composition (\% total identified fatty acids) (mean $\pm S E ; n=6$ ) in the tailfat of two fat-tailed sheep breeds, Mehraban and Sanjabi

\begin{tabular}{|c|c|c|c|}
\hline Fatty acids & Mehraban & Sanjabi & $P$-value \\
\hline C10:0 & $0.41 \pm 0.03$ & $0.42 \pm 0.04$ & 0.917 \\
\hline C12:0 & $0.22 \pm 0.03$ & $0.20 \pm 0.01$ & 0.471 \\
\hline C14:0 & $4.31 \pm 0.41$ & $4.28 \pm 0.15$ & 0.947 \\
\hline C14:1 & $0.76 \pm 0.15$ & $1.12 \pm 0.04$ & 0.044 \\
\hline C15:0 & $0.87 \pm 0.14$ & $1.58 \pm 0.14$ & 0.004 \\
\hline C16:0 & $26.5 \pm 0.95$ & $25.7 \pm 0.57$ & 0.495 \\
\hline C16:1 & $3.04 \pm 0.46$ & $4.24 \pm 0.44$ & 0.07 \\
\hline C17:0 & $0.38 \pm 0.03$ & $0.70 \pm 0.12$ & 0.01 \\
\hline C17:1 & $3.39 \pm 0.37$ & $5.39 \pm 0.36$ & 0.007 \\
\hline C18:0 & $11.01 \pm 1.72$ & $7.11 \pm 1.02$ & 0.069 \\
\hline C18:1n-9 & $40.01 \pm 1.22$ & $39.16 \pm 1.24$ & 0.606 \\
\hline C18:1t-11 & $3.41 \pm 0.38$ & $3.84 \pm 0.39$ & 0.505 \\
\hline C18:2n-6 & $3.93 \pm 0.40$ & $4.35 \pm 0.23$ & 0.381 \\
\hline C18:3n-6 & $0.35 \pm 0.07$ & $0.35 \pm 0.06$ & 0.954 \\
\hline c-9 t-11CLA & $1.18 \pm 0.22$ & $1.50 \pm 0.14$ & 0.249 \\
\hline c-12 t-10CLA & $0.17 \pm 0.08$ & $0.15 \pm 0.01$ & 0.786 \\
\hline C18:3n-3 & $0.53 \pm 0.07$ & $0.59 \pm 0.05$ & 0.502 \\
\hline C20:4n-6 & $0.21 \pm 0.04$ & $0.18 \pm 0.01$ & 0.477 \\
\hline C20:5n-3 & $0.24 \pm 0.09$ & $0.29 \pm 0.08$ & 0.713 \\
\hline C22:5n-3 & $0.14 \pm 0.04$ & $0.25 \pm 0.11$ & 0.279 \\
\hline$C 22: 6 n-3$ & $0.13 \pm 0.02$ & $0.12 \pm 0.02$ & 0.873 \\
\hline Total SFA & $43.7 \pm 1.99$ & $40.0 \pm 1.24$ & 0.136 \\
\hline Total UFA & $56.3 \pm 1.99$ & $60.0 \pm 1.24$ & 0.136 \\
\hline Total MUFA & $50.6 \pm 1.94$ & $53.8 \pm 1.17$ & 0.188 \\
\hline Total n-3 PUFA & $1.04 \pm 0.15$ & $1.25 \pm 0.16$ & 0.318 \\
\hline Total n-6 PUFA & $4.14 \pm 0.44$ & $4.52 \pm 0.23$ & 0.454 \\
\hline Total PUFA & $5.18 \pm 0.50$ & $5.77 \pm 0.32$ & 0.335 \\
\hline Total trans FA & $3.41 \pm 0.38$ & $3.84 \pm 0.39$ & 0.505 \\
\hline Total CLA & $1.35 \pm 0.24$ & $1.64 \pm 0.14$ & 0.306 \\
\hline n-6 : n-3 ratio & $4.19 \pm 0.43$ & $3.75 \pm 0.35$ & 0.43 \\
\hline UFA: SFA ratio & $1.31 \pm 0.10$ & $1.51 \pm 0.08$ & 0.148 \\
\hline PUFA: SFA ratio & $0.12 \pm 0.01$ & $0.15 \pm 0.01$ & 0.147 \\
\hline
\end{tabular}

SE: standard error; CLA: conjugated linoleic acid; UFA: unsaturated FAs;

SFA: saturated FAs; MUFA: monounsaturated FAs; PUFA: polyunsaturated FAs.

Total SFA $=$ sum of C10:0 + C12:0 + C14:0 + C15:0 + C16:0 + C17:0 + C18:0;

Total UFA = sum of C14:1 + C16:1 + C17:1 + C18:1n-9 + C18:2n-6 + C18:3n-3 + C20:4n-6

+C20:5n-3 + C22:5-3 + C22:6n-3; Total MUFA = sum of C14:1 + C16:1 + C17:1 + C18:1n-9;

Total n-3 PUFA = sum of C18:3n-3 + C20:5n-3 +C22:5n-3 +C22:6n-3;

Total n-6 PUFA = sum of C18:2n-6+C18:3n-6+C20:4n-6;

Total PUFA = C18:2n-6+C18:3n-6+C18:3n-3 +C20:4n-6+C20:5n-3 + C22:5n-3 + C22:6n-3;

Total trans $F A=$ sum of $C 18: 1 \mathrm{t}-11$;

Total CLA = sum c-9 t-11CLA c-9 t-11+ c-12 t-10CLA;

$n-6: n-3$ ratio = total $n-6$ PUFA; total $n-3$ PUFA. 
The concentration of c-9 t-11 CLA isomer in the Sanjabi subcutaneous adipose was twofold higher than in the Mehraban. Although the difference was not significant, the level of trans vaccenic acid (TVA) (C18:1t-11) was higher in the Sanjabi breed. TVA (C18:1t-11) is an important MUFA for de novo synthesis of CLA (c-9 t-11CLA), which is a potent anti-carcinogen that is synthesized in the subcutaneous adipose tissues (Bauman \& Lock 2006). These results are consistent with the study of Schen et al. (2007), who reported tissue and breed-specific responses in terms of TVA and CLA in cattle fed either a pasture or a concentrate diet. Breed differences in CLA content were also reported by Danc et al. (2009), who demonstrated the highest c-9 t-11 CLA level in the subcutaneous adipose tissues of Longhorn cattle compared with Charolais cross, Belted Galloway and Shorthorn cattle.

\section{Conclusion}

In the present study, differences between the sheep breeds in their FA profiles and c-9 t-11 CLA were observed in the adipose tissue, but not in the tailfat. Subcutaneous adipose tissue from Sanjabi lamb had a higher proportion of healthy linoleic and $\alpha$-linolenic acid, polyunsaturated FAs and cis-9 trans-11 CLA isomer. However, there were minimal differences in FA profiles of tailfat in the two breeds. It would be interesting to investigate ways to genetically or managerially manipulate the FA profile in fat-tailed breeds so that their product is more health promoting.

\section{Acknowledgments}

The authors are grateful to the Faculty of Agriculture at the Razi University, Kermanshah, Iran. They also acknowledge the Faculty of Veterinary Medicine, Universiti Putra Malaysia, for providing them with laboratory facilities and financial support.

\section{References}

Alipanah, M. \& Kashan, N.E., 2011. Fatty acid composition of fat tail, visceral and meat fat of three Iranian sheep breeds. J. Food. Agric. Environ. 9, 416-418.

AOAC, 1990. Official methods of analysis of the Association of Official Analytical Chemists $\left(15^{\text {th }}\right.$ ed.). Association of Official Analytical Chemists, Washington D.C., USA.

AOAC, 2007. Official methods of analysis of the Association of Official Analytical Chemists $\left(18^{\text {th }}\right.$ ed.). Association of Official Analytical Chemists, Washington D.C., USA.

Bauman, D.E. \& Lock, A.L., 2006. Conjugated linoleic acid: biosynthesis and nutritional significance. In: Advanced Dairy Chemistry, Volume 2: Lipids. Springer, New York. pp. 93-136.

Bulliyya, G., 2000. Key role of dietary fats in coronary heart disease under progressive urbanization and nutritional transition. Pac. J. Clinic Nutr. 9, 289-297.

Burr, G.O., 1973. A new deficiency disease produced by the rigid exclusion of fat from the diet. Nutr. Rev. $31,148-149$.

Dance, L.J.E., Matthews, K.R. \& Doran, O., 2009. Effect of breed on fatty acid composition and stearoyl-CoA desaturase protein expression in the semimembranosus muscle and subcutaneous adipose tissue of cattle. Livest. Sci. 125, 291-297.

Demirel, G., Wachira, A.M., Sinclair, L.A., Wilkinson, R.G., Wood, J.D. \& Enser, M., 2004. Effects of dietary $\mathrm{n}-3$ polyunsaturated fatty acids, breed and dietary vitamin $\mathrm{E}$ on the fatty acids of lamb muscle, liver and adipose tissue. Br. J. Nutr. 91, 551-565.

Ebrahimi, M., Rajion, M.A., Goh, Y.M. \& Sazili, A.Q., 2012. Impact of different inclusion levels of oil palm (Elaeis guineensis Jacq.) fronds on fatty acid profiles of goat muscles. J. Anim. Physiol. Anim. Nutr. 96, 962-969.

Ebrahimi, M., Rajion, M.A., Goh, Y.M., Sazili, A.Q. \& Schonewille, J.T., 2013. Effect of linseed oil dietary supplementation on fatty acid composition and gene expression in adipose tissue of growing goats. Biomed. Res. Int. 2013.

Fisher, A.V., Enser, M., Richardson, R.I., Wood, J.D., Nute, G.R., Kurt, E., Sinclair, L.A. \& Wilkinson, R.G., 2000. Fatty acid composition and eating quality of lamb types derived from four diverse breed $x$ production systems. Meat Sci. 55, 141-147.

Folch, J., Lees, M. \& Sloane-Stanley, G.H., 1957. A simple method for the isolation and purification of total lipids from animal tissues. J. Biol. Chem. 226, 497-509.

Fu, Z. \& Sinclair, A.J., 2000. Increased alpha-linolenic acid intake increases tissue alpha-linolenic acid content and apparent oxidation with little effect on tissue docosahexaenoic acid in the guinea pig. Lipids 35 (4), 395-400. 
Hansen, H.S. \& Jensen, B., 1985. Essential function of linoleic acid esteried in acylglucosylceramide and acylceramide in maintaining the epidermal water permeability barrier. Evidence from feeding studies with oleate, linoleate, arachidonate, columbinate, and a-linolenate, Biochim. Bioph. Acta 34, 357-363.

Healy, D.A., Wallace, F.A., Miles, E.A., Calder, P.C. \& Newsholme, P., 2000. Effect of low-to-moderate amounts of dietary fish oil on neutrophil lipid composition and function. Lipids 35, 763-768.

Holman, R.T., 1977. Essential fatty acids in human nutrition. In: Function and Biosynthesis of Lipids. Springer, New York. pp. 515-534.

Kelley, N.S., Hubbard, N.E. \& Erickson, K.L., 2010. Alteration of human body composition and tumorigenesis by isomers of conjugated linoleic acid. In: Modern Dietary Fat Intakes in Disease Promotion. Springer, New York. pp. 121-131.

Laborde, F.L., Mandell, I.B., Tosh, J.J., Wilton, J.W. \& Buchanan-Smith, J.G., 2001. Breed effects on growth performance, carcass characteristics, fatty acid composition, and palatability attributes in finishing steers. J. Anim. Sci. 79, 355-365.

Maroufyan, E., Kasim, A., Ebrahimi, M., Loh, T.C., Hair-Bejo, M. \& Soleimani, A.F., 2012. Dietary methionine and $n-6: n-3$ polyunsaturated fatty acid ratio reduce adverse effects of infectious bursal disease in broilers. Poult. Sci. 91, 2173-2182.

NRC, 1985. Nutrient requirements of sheep. ( $6^{\text {th }}$ ed.). National Academy Science, Washington, D.C., USA.

NRC, 2001. Nutrient requirement of sheep. ( $7^{\text {th }}$ ed.). National Academy Science, Washington DC, USA.

Nuernberg, K., Fischer, A., Nuernberg, G., Ender, K. \& Dannenberger, D., 2008. Meat quality and fatty acid composition of lipids in muscle and fatty tissue of Skudde lambs fed grass versus concentrate. Small Rumin. Res. 74, 279-283.

Peng, Y.S., Brown, M.A., Wu, J.P. \& Liu, Z., 2010. Different oilseed supplements alter fatty acid composition of different adipose tissues of adult ewes. Meat Sci. 85, 542-549.

Rajion, M.A., McLean, J.G. \& Cahill, R.N., 1985. Essential fatty acids in the fetal and newborn lamb. Aust. J. Boil. Sci. 38, 33-40.

Ruxton, C.H.S., Reed, S.C., Simpson, M.J.A. \& Millington, K.J., 2004. The health benefits of omega-3 polyunsaturated fatty acids: a review of the evidence. J. Hum. Nutr. Diet. 17, 449-459.

Saatchi, M., Garrick, D.J., Tait, R.G., Mayes, M.S., Drewnoski, M., Schoonmaker, J., Diaz, C., Beitz, D.C. \& Reecy, J.M., 2013. Genome-wide association and prediction of direct genomic breeding values for composition of fatty acids in Angus beef cattle. BMC Genomics 14, 730.

Sanudo, C., Enser, M.E., Campo, M.M., Nute, G.R., Marıa, G., Sierra, I. \& Wood, J.D., 2000. Fatty acid composition and sensory characteristics of lamb carcasses from Britain and Spain. Meat Sci. 54, 339-346.

SAS, 2003. SAS User's Guide: Statistics, Version 9.1 edition. SAS Inst., Inc., Cary, NC, USA.

Schen, X., Nuernberg, K., Nuernberg, G., Zhao, R., Scollan, N., Ender, K. \& Dannenberger, D., 2007. Vaccenic acid and cis-9, trans-11 CLA in the rumen and different tissues of pasture- and concentratefed beef cattle. Lipids 42, 1093-1103.

Susana, P., Alves, S.P., Bessa, R.J.B., Quaresma, M.A.G., Kilminster, K., Scanlon, T., Oldham, C., Milton, J., Greeff, J. \& Almeida, A.M., 2013. Does the fat tailed Damara ovine breed have a distinct lipid metabolism leading to a high concentration of branched-chain fatty acids in tissues? PLOS ONE 8(10): e77313. doi:10.1371/journal.pone.0077313.

Van Soest, P., Robertson, J.B. \& Lewis, B.A., 1991. Methods for dietary fiber, neutral detergent fiber, and nonstarch polysaccharides in relation to animal nutrition. J. Dairy Sci. 74, 3583-3597.

Wachira, A.M., Sinclair, L.A., Wilkinson, R.G., Enser, M., Wood, J.D. \& Fisher, A.V., 2002. Effects of dietary fat source and breed on the carcass composition, n-3 polyunsaturated fatty acid and conjugated linoleic acid content of sheep meat and adipose tissue. Br. J. Nutr. 88, 697-709.

Wahle, K.W., Heys, S.D. \& Rotondo, D., 2004. Conjugated linoleic acids: are they beneficial or detrimental to health? Prog. Lipid Res. 43, 553-587. 